\title{
Patterns and Dynamics of Plant Diversity and Soil Physical-Chemical Properties of the Karst Rocky Desertification Ecosystem, SW China
}

\author{
Lin-Jiao Wang ${ }^{1,3}$, Mao-Yin Sheng ${ }^{1,2^{*}}$, Shuang Li ${ }^{1,2}$, Jing Wu ${ }^{1,3}$ \\ 'Institute of Karst Research, Guizhou Normal University, Guiyang, 550001, the People's Republic of China \\ ${ }^{2}$ National Engineering Research Center for Karst Rocky Desertification Control, Guiyang, 550001, \\ the People's Republic of China \\ ${ }^{3}$ State Key Laboratory Incubation Base for Karst Mountain Ecology Environment of Guizhou Province, Guiyang, \\ 550001, the People's Republic of China
}

Received: 23 March 2020

Accepted: 20 June 2020

\begin{abstract}
Three typical rocky desertification regions of South China Karst were selected as experiment sites. Ninety plots, each with an area of $20 \mathrm{~m} \times 20 \mathrm{~m}$, representative of the five degrees of rocky desertification (nil, potential, slight, moderate and severe) were established, and plant diversity and soil physicalchemical properties were surveyed and analyzed. The vegetation of rocky desertification ecosystems proved to be very simple with an extremely low species richness index. With increased degree of rocky desertification, there are remarkable changes in plant diversity: species number declines; the ratio of dominant species importance value is higher; species composition becomes more disorder. There are significant differences in plant diversity indices among different degrees of rocky desertification. On the large scale, evenness and dominance indices of plant diversity increase and the Shannon-Wiener index decreases along the increased gradient of desertification. There were also significant differences in soil physical-chemical properties among the five degrees of desertification. Both physical and chemical properties do not always degenerate with increased degree of rocky desertification. Instead, properties initially degenerate and then improve. And there was a remarkable correlation between soil physicalchemical properties and plant diversity. All these offer bases to clarify the evolution law and formation mechanism of plant diversity and soil physical-chemical properties in karst rocky desertification ecosystem, and have extremely important value in the rehabilitation of the karst rocky desertification ecosystem.
\end{abstract}

Keywords: Karst, rocky desertification, plant diversity, soil physical-chemical properties, Succession

*e-mail: shmoy@163.com 


\section{Introduction}

Karst is a distinctive topography in which the landscape is largely shaped by the dissolving action of water on carbonate bedrock (usually limestone, dolomite, or marble). This geological process, occurring over many thousands of years, results in unusual surface and subsurface features ranging from sinkholes, vertical shafts, disappearing streams, and springs, to complex underground drainage systems and caves [1]. South China Karst with the area of approximate $540,000 \mathrm{~km}^{2}$, centered of Guizhou province and covering Guangxi, Yunnan, Sichuan, Hunan, Guangdong, Jiangxi, Hubei, and Chongqing provinces of China, is the largest region of bare carbonate rock among the three karst concentrated distribution areas in the whole world, and is an extreme fragile eco-environment system with large altitude gradient and complex landscape pattern formed from Qinghai-Tibet Plateau uplifted in South Asia subtropical climate zone [1,2]. The soil layer is very thin and the pedogenesis rate is extremely slow with a high risk of soil erosion. So South China Karst is a very typical fragile ecological zone of non-zonality with serious land degradations [3, 4].

Karst rocky desertification (KRD) is defined to be a special type of severe land degradation in warm and humid subtropical karst areas that is normally characterized by rapid soil loss, widely exposed bedrocks, decreasing land productivity, and fast expansion of desert-like landscape [5, 6]. As a typical sort of land degradation, KRD is one of the most threatening environmental issues in limestone areas, as a consequence of serious soil erosion, extensive exposure of basement rocks, drastic decrease in soil productivity, and the appearance of a desert-like landscape due to irrational, intensive land use on a fragile karst eco-environment, especially in warm tropical and subtropical karst mountain areas with abundant rainfall [5, 7, 8]. At present, in South China Karst, there are more than 100 million inhabitants lived, involving about 48 ethnic minorities, with lots of poverty distributed, and the contradiction between population and land resources is very strong $[5,9]$. Once the slope vegetation destroyed, the soil erosion will increase acutely, leading to the thin soil layer all lost and rocky desertification arise with the rapid decrease of water and nutrient storage capacity of the ecosystem. Rocky desertification of South China Karst has become a serious ecological issue, gravely hindering the local sustainable development of economy and society $[5,10]$. The control of rocky desertification has been clearly listed in the Chinese national plans of economy and society development and become an important work of the local society and economy constructions [2].

However, in the control of rocky desertification, China government has invested the massive manpower, financial and material capabilities, but the total tendency of rocky desertification do not keep down absolutely and the control results are unsatisfactory with some

\begin{tabular}{|c|c|c|c|}
\hline 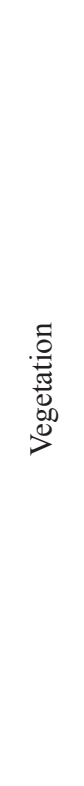 & 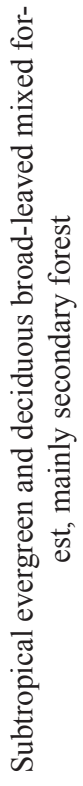 & 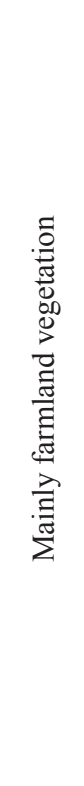 & 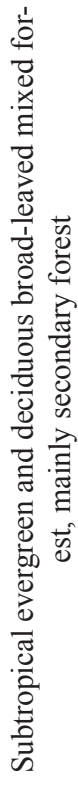 \\
\hline 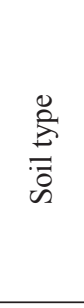 & 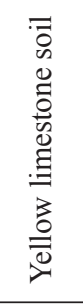 & 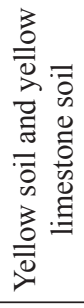 & 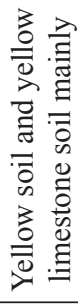 \\
\hline 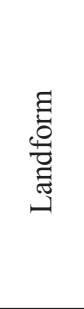 & 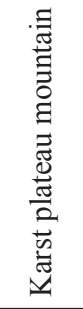 & 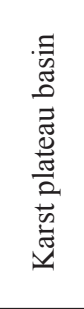 & 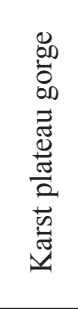 \\
\hline 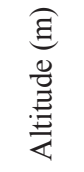 & 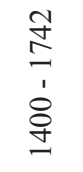 & $\begin{array}{l}\overrightarrow{\vec{n}} \\
\vec{i} \\
\vec{\Xi}\end{array}$ & 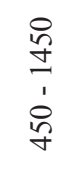 \\
\hline 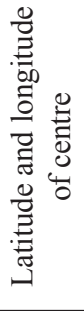 & 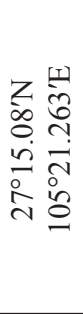 & 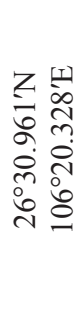 & 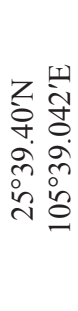 \\
\hline 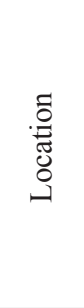 & 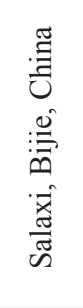 & 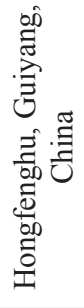 & 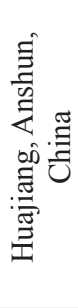 \\
\hline 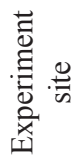 & $\neg$ & 二 & 二 \\
\hline
\end{tabular}


serious problems, such as, the ecosystem structure of rocky desertification rehabilitation is very simple, the stabilization very bad, and the resistibility extreme feeble, and so on $[2,11,12]$. All these can be attributed to that the controls of rocky desertification seriously lack the scientific support of the biodiversity reconstruction [13-15]. But so far, there are very short of exhaustive studies on restoration ecology of rocky desertification $[16,17,18]$. Although there are lots of researches on the single ecology process of karst ecosystem, there are short of works on biodiversity and soil physicalchemical properties of karst rocky desertification ecosystem [19, 20], especially, the stabilization and degeneration mechanism of biodiversity [21, 22]. Until now, the patterns and dynamics of biology community structure and soil physical-chemical properties in the progression of karst rocky desertification ecosystem still are not clear $[13,23]$, and there is still no research on the biodiversity reconstruction in the rehabilitation of rocky desertification. So, in this study, three typical rocky desertification areas in South China Karst were selected as experiment sites, and the plant diversity and physical-chemical properties were surveyed and analyzed to research the patterns, dynamics and response mechanisms of plant diversity and soil physical-chemical properties in the succession of rock desertification. Results can evaluate the degree of degeneration of karst plant ecosystem and may play a useful role in determining vegetation rehabilitation techniques.

\section{Materials and Methods}

\section{Study Area}

The typical rocky desertification region in South China Karst was selected as study area. In the study area, three experiment sites, namely, Salaxi (Site I), Hongfenghu (Site II), and Huajiang (Site III) were selected. The location and basic information of the three experiment sites are presented in Table 1 and Fig. 1. Experiment site $I$ is located at the rural area of Salaxi town with a distance of $13 \mathrm{~km}$ from Bijie city, Guizhou province, China. The total area of this site is $41.52 \mathrm{~km}^{2}$, in which, the area of karst is $26.36 \mathrm{~km}^{2}$, specifically, Nil RD $7.19 \mathrm{~km}^{2}$ (17.32\% of total area), Pot RD $8.93 \mathrm{~km}^{2}$ (21.51\% of total area), Sli RD $7.96 \mathrm{~km}^{2}(19.16 \%$ of total area), Mod RD $1.74 \mathrm{~km}^{2}$ (4.18\% of total area), and Sev RD $0.54 \mathrm{~km}^{2}$

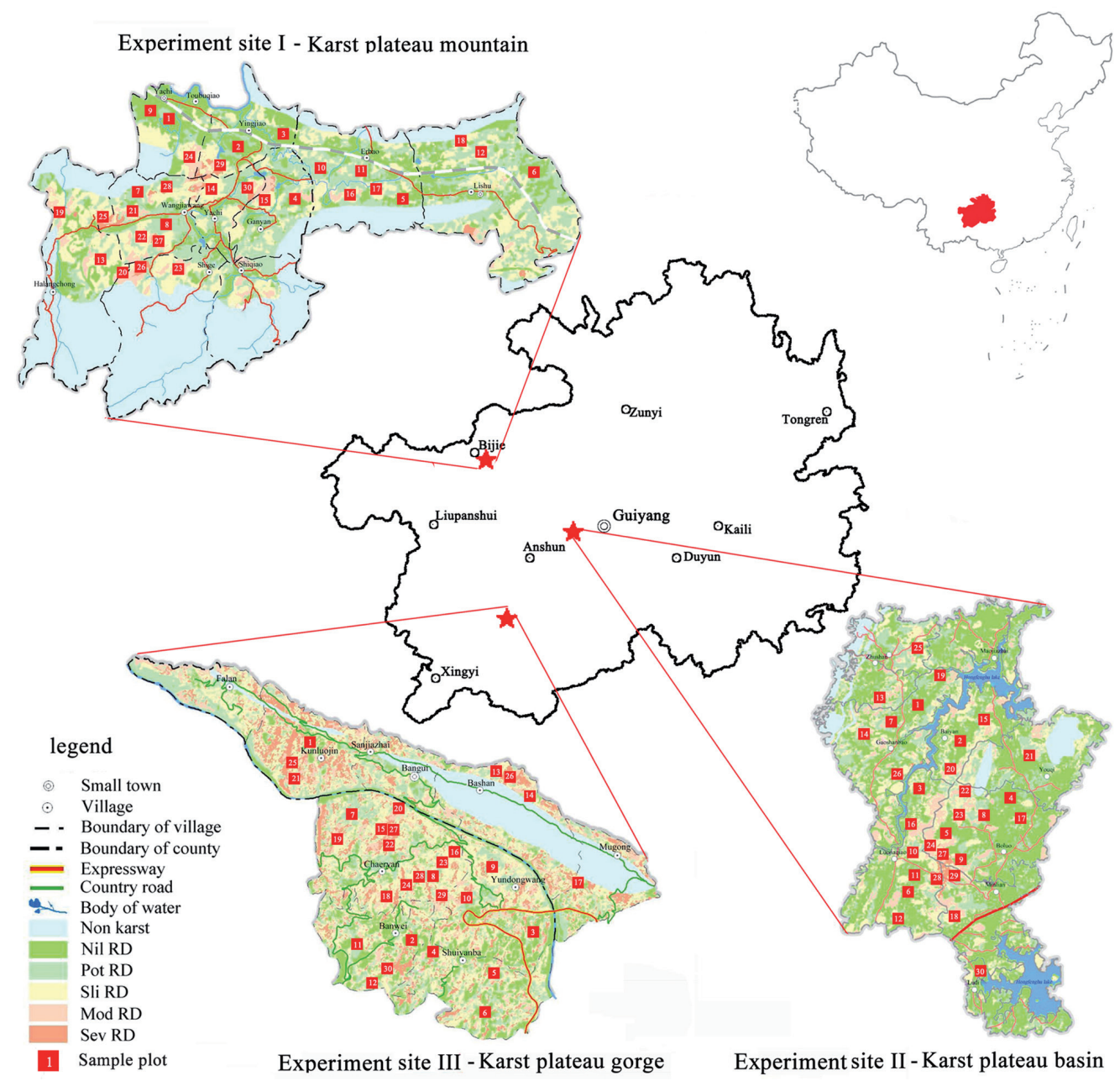

Fig. 1. Location and rocky desertification distribution of the experiment sites and sample plots. 
(1.31\% of total area). At this site, a karst plateau mountain is the main landform, the terrain is large and undulating, and the altitude ranges from 1,400 $\mathrm{m}$ to $1,742 \mathrm{~m}$. The annual rainfall ranges from $618 \mathrm{~mm}$ to $995 \mathrm{~mm}$, with an average of about $863 \mathrm{~mm}$. Rainfall is mainly distributed from July to September and accounts for $52 \%$ of the total annual rainfall. The rock is mainly composed of carbonate with partially distributed purple sand shale of Jurassic. The soil is mainly composed of yellow soil and purple sandy soil. The vegetation is subtropical evergreen and deciduous broad-leafed mixed forest, and the forest is mainly a secondary forest because the original vegetation has basically been destroyed. Wild shrub vegetation is mainly composed of Pyracantha fortuneana (Maximowicz) H. L. Li, Rosa roxbunghii Trattinnick and Clematis florida Thunb., and the forest is mainly composed of species of genera Cyclobalanopsis, Pinus, and Betula.

Experiment site II is located at the rural area of Hongfeng town with a distance $12 \mathrm{~km}$ from Qingzhen city, Guizhou province, China. The total area of this site is $60.44 \mathrm{~km}^{2}$, in which, the area of karst is $57.45 \mathrm{~km}^{2}$, specifically, Nil RD $32.36 \mathrm{~km}^{2}$ (53.54\% of total area), Pot RD $9.91 \mathrm{~km}^{2}$ (16.40\% of total area), Sli
RD $9.24 \mathrm{~km}^{2}$ (15.28\% of total area), Mod RD $5.55 \mathrm{~km}^{2}$ (9.15\% of total area), and Sev RD $0.41 \mathrm{~km}^{2}(0.68 \%$ of total area). The landform is the typical karst plateau basin with moderate slopes and dam fields. The greatest relative height is about $180 \mathrm{~m}$, with altitude ranging from $1,271 \mathrm{~m}$ to $1,451 \mathrm{~m}$. The annual average rainfall is about $1,215 \mathrm{~mm}$, mainly distributed in the period of April to August and accounting for $75 \%$ of the total annual rainfall. The rock is dolomite, argillaceous dolomite, or shale of Triassic, and the soil is mainly composed of yellow soil and yellow limestone soil. In the natural vegetation community, the tree layer is mainly composed of Cupressus funebris Endl.. The shrub layer that has typical limestone characteristics is composed of species Viburnum chinshanense Graebn., Pyracantha fortuneana (Maxim.) Li, Ficus tikoua Bur., Rosa multiflora Thunb., Rubus corchorifolius L. f., Rhamnus hemsleyana Schneid., and so on. The common species of herbaceous layer are Imperata cylindrica (L.) Beauv., Miscanthus floridulus (Lab.) Warb. ex Schum. et Laut., Miscanthus sinensis Anderss., Arthraxon hispidus (Thunb.) Makino, and C. florida.

Experiment site III is located on both sides of the Beipanjiang River with a distance of $10 \mathrm{~km}$ from
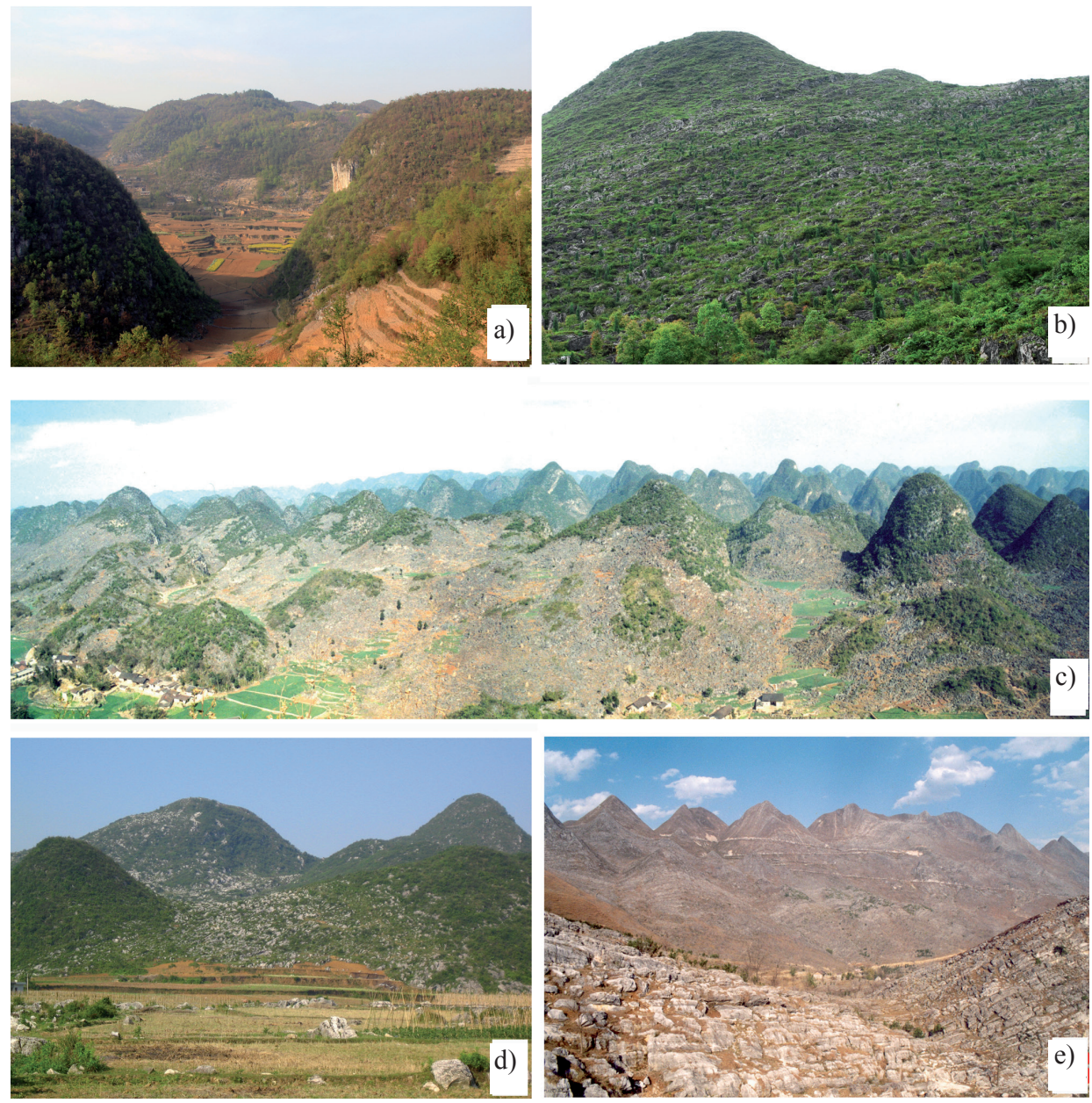

Fig. 2. Landscapes of karst rocky desertification. A. Nil rocky desertification; B. Potential rocky desertification; C. Moderate rocky desertification; D. Slight rocky desertification; E. Severe rocky desertification. 
Huajiang Town, Anshun City, China. The total area of this site is $51.62 \mathrm{~km}^{2}$, in which, the area of karst is $45.06 \mathrm{~km}^{2}$, specifically, Nil RD $7.65 \mathrm{~km}^{2}(14.82 \%$ of total area), Pot RD $9.50 \mathrm{~km}^{2}$ (18.41\% of total area), Sli RD $15.19 \mathrm{~km}^{2}$ (29.44\% of total area), Mod RD $6.40 \mathrm{~km}^{2}$ (12.40\% of total area), and Sev RD $6.63 \mathrm{~km}^{2}$ $(12.85 \%$ of total area). The karst plateau gorge is the main landform. The greatest relative height is about $1,000 \mathrm{~m}$ with altitude ranging from $450 \mathrm{~m}$ to $1,450 \mathrm{~m}$. The annual average rainfall is about $1,100 \mathrm{~mm}$ mainly distributed from May to October and accounts for $83 \%$ of the total annual rainfall. The rock is mainly dolomite, argillaceous dolomite, and shale of Triassic. The soil is mainly composed of yellow soil and yellow limestone soil. The vegetation is subtropical evergreen and deciduous broad-leafed mixed forest, and the forest is mainly secondary forest because the original vegetation has been critically destroyed. Wild shrubs are mainly composed of Pyracantha angustifolia (Franch.) Schneid., P. fortuneana, $R$. roxbunghii, $C$. florida, and so on, and the high forest fragmentarily distributed are mainly composed of species of the genera Cyclobalanopsis, Pinus, and Betula.

\section{Rocky Desertification Classification and Sample Plots}

Xiong et al. (2002) [11] proposed that the KRD should be classified from four factors: percentage of vegetation, slope, percentage of bare rock and average depth of top soil. According to the factor, this paper classified the KRD into five degrees, i.e., (1) nil rocky desertification (Nil RD); (2) potential rocky desertification (Pot RD); (3) slight rocky desertification (Sli RD); (4) moderate rocky desertification (Mod $\mathrm{RD})$; (5) severe rocky desertification (Sev RD), and the threshold of each degree was listed in Table 2. Aiming on these five typical degrees of rocky desertification (Fig. 2), ninety sample plots, each with an area of $20 \mathrm{~m} \times 20 \mathrm{~m}$, were set up in the three experiment sites. In per experiment site, 6 sample plots for per degree of rocky desertification were set up, respectively. From 2008 to 2012, the plant diversity and the soil physicalchemical properties were studied in these ninety sample plots. Based on the classification standard of rocky desertification (Table 2), the rocky desertification degree of the ninety sample plots all did not change in the duration.

\section{Plant Diversity Survey and Calculation}

Based on the ninety sample plots, the plant diversity were surveyed in January and August of 2012, respectively, by the method of field monitoring. To evaluate the plant diversity, the four indices are calculated, that is, Richness index $(R, R=S)$, Shannon -Wiener index $\left(H, H=-\sum_{i=1}^{S} P i \log P i\right)$, Evenness index $(E, E=\mathrm{H} / \ln S)$, and Dominance in'dex $\left.\left(D, D=\sum^{S} P i^{2}\right)\right)$. In these formulas, $S$ is the number of speciề $\mathrm{Pi}(\mathrm{Pi}=\mathrm{Ni} / \mathrm{N})$ is the relative importance value of species, where $N i$ is the important value of species, and $N$ is the sum of $N i$; the important value $(N i)=R D E+R D O+R F E$, $R D E$ is relative density, $R D O$ is relative dominance (cross-sectional area at breast height), RFE is relative frequency.

\section{Soil Sampling and Physical-Chemical Properties Determination}

Three sample points were selected by the method of S-shaped in the center of each plot and the distance is smaller than $5 \mathrm{~m}$ between points. The soil of $0 \sim 15 \mathrm{~cm}$ depth in each point is collected with three repeats by ring knifes and is mixed into the tested sample. For the soil layer is very thin, partly about $15 \mathrm{~cm}$ depth, in rocky desertification ecosystem, the samples only be collected in the depth of $0 \sim 15 \mathrm{~cm}$ in the present study. Nine soil physical factors are selected to determined, that is, bulk density, capillary porosity, non-capillary porosity, total porosity, natural moisture capacity, field moisture capacity, capillary moisture capacity, upper strata saturated permeability and lower strata saturated permeability. In the determination of soil chemical properties, nine factors are also selected: $\mathrm{pH}$, organic matter content, total nitrogen content, total phosphorus content, total potassium content, hydrolyzed nitrogen content, available phosphorus content, available potassium content, and soil respiration. These soil physical-chemical properties are determined by the methods of Liu (1996) [24], Chen et al. (2012) [25], Li et al. (2016) [26], and Wang et al. (2018) [27], respectively.

Table 2. Classification standard of Karst rocky desertification.

\begin{tabular}{|c|c|c|c|c|c|}
\hline \multirow{2}{*}{ Parameter } & \multicolumn{5}{|c|}{ The standard of the Karst rocky desertification } \\
\cline { 2 - 6 } & Nil & Potential & Slight & Moderate & Severe \\
\hline Percentage of vegetation (\%) & $>80$ & $<80$ & $<70$ & $<50$ & $<30$ \\
\hline Slop $\left(^{\circ}\right)$ & $<15$ & $>15$ & $>15$ & $>20$ & $>25$ \\
\hline Percentage of bare rock (\%) & $<20$ & $>20$ & $>40$ & $>60$ & $>80$ \\
\hline Average depth of top soil $(\mathrm{cm})$ & $>20$ & $<20$ & $<15$ & $<10$ & $<5$ \\
\hline
\end{tabular}


Table 3. Vegetation structure and community composition of the three experiment sites studi

\begin{tabular}{|c|c|c|c|c|}
\hline \multirow{2}{*}{$\begin{array}{l}\text { Experiment } \\
\text { site }\end{array}$} & \multicolumn{2}{|c|}{ Herbage layer } & \multicolumn{2}{|c|}{ Woody layer } \\
\hline & Family & Number (Genus/Species) & Family & Number (Genus/Species) \\
\hline \multirow{14}{*}{ I } & Dicksoniaceae & $1 / 1$ & Guttiferae & $1 / 1$ \\
\hline & Nephrolepidaceae & $1 / 1$ & Fabaceae & $1 / 1$ \\
\hline & Fabaceae & $1 / 1$ & Berberidaceae & $1 / 1$ \\
\hline & Pteridaceae & $1 / 1$ & Juglandaceae & $1 / 1$ \\
\hline & Poaceae & $1 / 1$ & Betulaceae & $1 / 1$ \\
\hline & Asteraceae & $2 / 3$ & Fagaceae & $1 / 1$ \\
\hline & Dryopteridaceae & $1 / 1$ & Coriariaceae & $1 / 1$ \\
\hline & Lindsaeaceae & $1 / 1$ & Rosaceae & $7 / 7$ \\
\hline & Ranunculaceae & $1 / 1$ & Rutaceae & $1 / 1$ \\
\hline & Rosaceae & $1 / 1$ & Moraceae & $1 / 1$ \\
\hline & Cyperaceae & $1 / 1$ & Rhamnaceae & $1 / 1$ \\
\hline & Caryophyllaceae & $1 / 1$ & Pinaceae & $1 / 1$ \\
\hline & Polypodiaceae & $1 / 1$ & & \\
\hline & Adiantaceae & $1 / 1$ & & \\
\hline \multirow{16}{*}{ II } & Liliaceae & $2 / 2$ & Fabaceae & $1 / 1$ \\
\hline & Philydraceae & $1 / 1$ & Cupressaceae & $1 / 1$ \\
\hline & Scrophulariaceae & $1 / 1$ & Elaeagnaceae & $1 / 1$ \\
\hline & Boraginaceae & $1 / 1$ & Saxifragaceae & $1 / 1$ \\
\hline & Pteridaceae & $1 / 1$ & Betulaceae & $1 / 1$ \\
\hline & Poaceae & $2 / 3$ & Arecaceae & $1 / 1$ \\
\hline & Asteraceae & $2 / 3$ & Fagaceae & $1 / 1$ \\
\hline & Dryopteridaceae & $1 / 1$ & Coriariaceae & $1 / 1$ \\
\hline & Berberidaceae & $1 / 1$ & Rosaceae & $2 / 3$ \\
\hline & Ranunculaceae & $1 / 1$ & Caprifoliaceae & $2 / 4$ \\
\hline & Lardizabalaceae & $1 / 1$ & Rhamnaceae & $1 / 1$ \\
\hline & Umbelliferae & $1 / 1$ & Guttiferae & $1 / 1$ \\
\hline & Cyperaceae & $1 / 2$ & Araliaceae & $1 / 1$ \\
\hline & Nephrolepidaceae & $1 / 1$ & Berberidaceae & $1 / 1$ \\
\hline & & & Lauraceae & $1 / 1$ \\
\hline & & & Rutaceae & $2 / 2$ \\
\hline \multirow{10}{*}{ III } & Pteridaceae & $1 / 1$ & Euphorbiaceae & $2 / 3$ \\
\hline & Lygodiaceae & $1 / 1$ & Poaceae & $1 / 1$ \\
\hline & Poaceae & $3 / 3$ & Simaroubaceae & $1 / 1$ \\
\hline & Nephrolepidaceae & $2 / 2$ & Meliaceae & $1 / 1$ \\
\hline & Thelypteridaceae & $1 / 1$ & Anacardiaceae & $1 / 1$ \\
\hline & Asteraceae & $3 / 3$ & Solanaceae & $1 / 1$ \\
\hline & Adiantaceae & $1 / 1$ & Caprifoliaceae & $1 / 1$ \\
\hline & Oxalidaceae & $1 / 1$ & Moraceae & $2 / 2$ \\
\hline & Ranunculaceae & $1 / 1$ & Sapindaceae & $1 / 1$ \\
\hline & & & Rhamnaceae & $1 / 1$ \\
\hline
\end{tabular}




\section{Data analyses}

The variances of plant diversity indices and soil physical-chemical properties among different experiment sites and plots are compared by the method of a generalised linear model, $T$ test, and Duncan test. The correlation of plant diversity indices and physicalchemical properties were analyzed by the method of correlation analysis. And the principal component analysis was used to evaluate the ecological factors of rocky desertification ecosystem. All these statistical analyses were accomplished by the software of SPSS16.0 [28], and software of Excel 2007 was used to draw.

\section{Results}

\section{Plant Diversity}

\section{Vegetation Structure of Karst Rocky Desertification Ecosystem}

Results of vegetation structure surveyed in the three experiment sites were filled in Table 3. The vegetation structure of rocky desertification is very simple, and with increased degree of rocky desertification, the vegetation structure depress progressively. As expected, the vegetation structure of experiment site III (Huajiang) is most simple because that its rock desertification is most serious among the three experiment sites, in which the herbaceous layer only is composed of 14 species belonging to 14 genera and 9 families, and the tree layer composed of 13 species belonging to 12 genera and 10 families. Besides, the species richness in rocky desertification ecosystem also is very low. And the majority of families distributed in rocky desertification ecosystem only have one species lived, except that families of Asteraceae, Rosaceae, Poaceae, Caprifoliaceae, and Euphorbiaceae have more than one species lived, which show these taxa have better adaptability in rock desertification ecosystem. Besides, there are many species of family Rosaceae in the Pot RD and Sli RD, but in the Sev RD, the species distributed remarkably reduce.

\section{Comparisons of Plant Diversity between Different Experiment Sites}

The four indices of plant diversity of rocky desertification ecosystem all are very low. Comparisons of the four plant diversity indices among the three experiment sites were conducted by Duncan test (Fig. 3). Results show that there are significant differences of the four plant diversity indices among the three experiment sites. Specifically, the evenness (mean of 0.59 ) and dominance indices (mean of 0.12) of experiment site III (Huajiang), a typical Sev RD, are significantly smaller than those of experiment site I (Salaxi, mean of

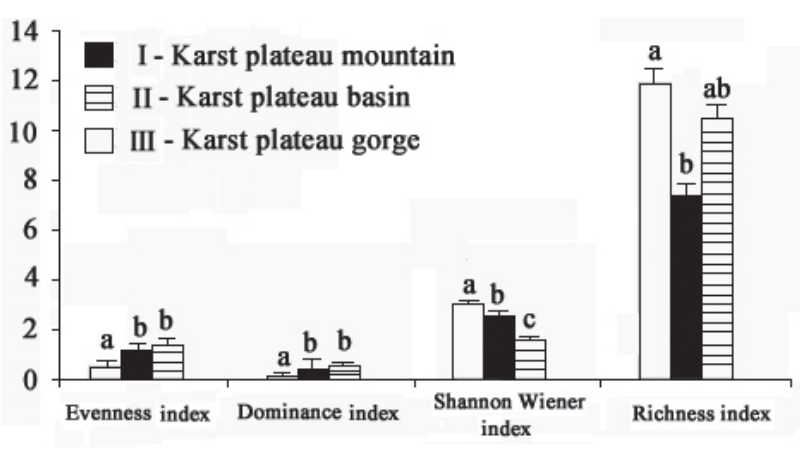

Fig. 3. Comparison of plant diversity between different experiment sites. There is no significant difference between sites with same letter, and there are significant differences between sites without same letter, the same below.

1.26 and 0.43 , respectively) and II (Hongfenghu, mean of 1.45 and 0.48 , respectively), typical Pot RD and Sli RD, respectively; the Shannon-Wiener index of experiment site III (mean of 3.13) is significantly more than that of experiment site I (mean of 2.65), and experiment site I significantly more than experiment site II (mean of 1.68); the richness index of experiment site III (mean of $11.92)$ is significantly more than that of experiment site I (mean of 7.46), and all no significant difference with that of experiment site II (mean of 10.58).

\section{Comparisons of Plant Diversity between Different Degrees of Rocky Desertification}

Comparisons of the four plant diversity indices between different degrees of rocky desertification by $F$ test and Duncan test were filled in Table 4. Results show there are significant differences of the four plant diversity indices between different degrees of rocky desertification. Specifically, for the evenness index, the descending order of value is Nil RD $>$ Pot RD $>$ Sli $\mathrm{RD}$, Mod RD and Sev RD, and the differences are significant; For the richness index, the value of Nil $\mathrm{RD}$ and Sli RD are significantly more than that of Pot RD; For Shannon-Wiener index, the value of Nil RD, Pot RD and Sli RD is significantly smaller than that of Sev RD, and there is no significant difference among Nil RD, Pot RD and Sli RD; For the dominance index, the value of Pot RD is significantly more than the others.

\section{Seasonal Dynamic of Plant Diversity in Rocky Desertification Ecosystem}

To obtain the seasonal dynamics of plant diversity in rocky desertification ecosystem, comparisons of the four plant diversity indices surveyed in two typical seasons of summer (August) and winter (January), respectively, from 2008 to 2012 were conducted by the statistical analysis of $T$ test (Table 5). Results show there are no significant difference of the four plant diversity indices between winter and summer. 
Table 4. Plant diversity indices of different degrees of rocky desertification

\begin{tabular}{|c|c|c|c|c|c|c|c|c|c|}
\hline \multirow{2}{*}{$\begin{array}{c}\text { Degree of } \\
\text { rocky } \\
\text { desertification }\end{array}$} & \multicolumn{2}{|c|}{$\begin{array}{c}\text { Evenness index } \\
(E)\end{array}$} & \multicolumn{2}{|c|}{$\begin{array}{c}\text { Richness index } \\
(R)\end{array}$} & \multicolumn{2}{|c|}{$\begin{array}{c}\text { Shannon-Wiener index } \\
(H)\end{array}$} & \multicolumn{2}{c|}{$\begin{array}{c}\text { Dominance index } \\
(D)\end{array}$} & $F$ test ${ }^{\text {II }}$ \\
& Mean & $S S R^{\mathrm{I}}$ & Mean & $S S R$ & Mean & $S S R$ & Mean & $S S R$ & \\
\hline Nil & 2.3436 & $\mathrm{a}$ & 12.6 & $\mathrm{a}$ & 2.2638 & $\mathrm{ab}$ & 0.2770 & $\mathrm{~b}$ & \\
\hline Potential & 1.3311 & $\mathrm{~b}$ & 6.5 & $\mathrm{~b}$ & 1.8157 & $\mathrm{a}$ & 0.5759 & $\mathrm{a}$ & $\mathrm{b}$ \\
\hline Slight & 0.3781 & $\mathrm{c}$ & 12.17 & $\mathrm{a}$ & 2.4840 & $\mathrm{ab}$ & 0.3173 & $\mathrm{~b}$ \\
\hline Moderate & 0.4221 & $\mathrm{c}$ & 10.75 & $\mathrm{ab}$ & 2.9076 & $\mathrm{bc}$ & 0.1717 & $\mathrm{~b}$ & $\mathrm{~b}$ \\
\hline Severe & 0.7469 & $\mathrm{c}$ & 9.2 & $\mathrm{ab}$ & 3.2828 & $\mathrm{c}$ & 0.1282 & $\mathrm{~b}$ \\
\hline
\end{tabular}

${ }^{\mathrm{I}}$ there is no significant difference between difference degrees with same letter and there are significant differences between difference degrees without same letter, the same below.

II ** indicate the significant difference at $\alpha=0.01$.

\section{Soil Physical-Chemical Properties}

\section{Comparisons of Soil Physical-Chemical Properties between Different Experiment Sites}

The soil physical-chemical properties of different experiment sites were compared by Duncan test (Fig. 4). Results show that there are significant differences of the ten soil physical-chemical factors, that is, capillary porosity, non-capillary porosity, upper strata saturated permeability, lower strata saturated permeability, $\mathrm{pH}$, available phosphorus content, total nitrogen content, total phosphorus content, hydrolyzed nitrogen content, and available potassium content, among the three experiment sites. The non-capillary porosity (mean of 23.21) and upper strata saturated permeability (mean of 16.32) of experiment site I are significantly more than those of site II (mean of 17.39 and 10.53, respectively) and III (mean of 15.65 and 7.15 , respectively); the $\mathrm{pH}$ (mean of 7.84), total nitrogen content (mean of 3.27 ) and total phosphorus content (mean of 0.99) of experiment site III are significantly more than those of site I (mean of 6.87, 2.25, and 0.58, respectively) and II (mean of 6.73, 2.43, and 0.65, respectively); the capillary porosity of experiment site I (mean of 32.10) is significantly smaller than that of site II (mean of 37.45) and III (mean of 40.09); the lower strata saturated permeability of experiment site III (mean of 2.24) is significantly smaller than that of site I (mean of 12.36) and II (mean of 8.15); the available phosphorus content of experiment site II (mean of 2.56) is significantly smaller than that of site I (mean of 5.86) and III (mean of 7.20); the hydrolyzed nitrogen content of experiment site I (mean of 141.18) is significantly smaller than that of site II (mean of 204.65), and all no significant difference with that of site III (mean of 167.40); the available potassium content of experiment site I (mean of 113.21) is significantly more than that of site II (mean of 95.08), and all no significant difference with that of site III (mean of 100.48).

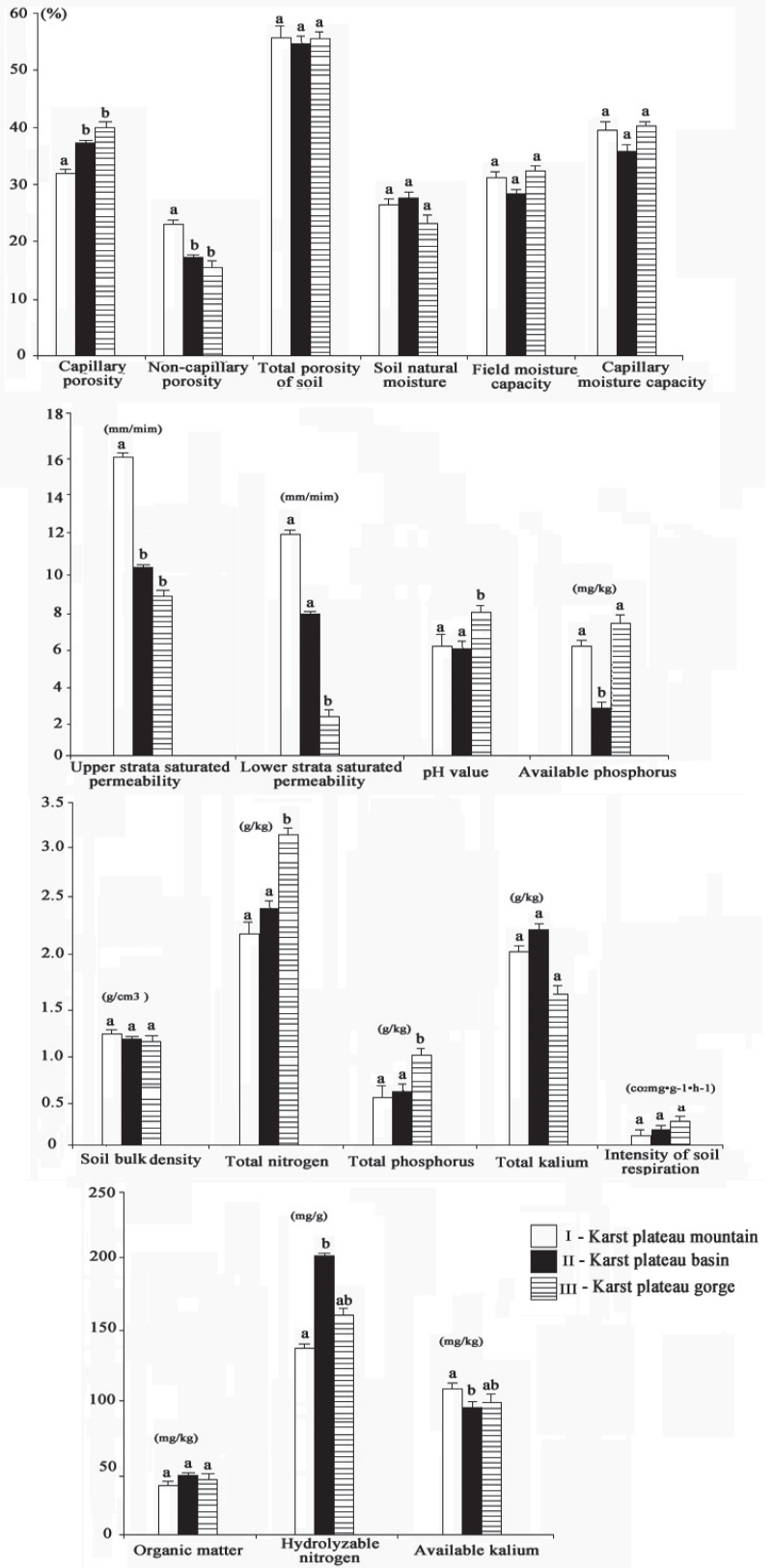

Fig. 4. Comparison of soil physical-chemical properties between different experiment sites. 
Table 5. Comparison of plant diversity, soil physical-chemical properties in rocky desertification ecosystem between summer (August) and winter (January).

\begin{tabular}{|c|c|c|c|c|c|c|c|c|}
\hline \multirow[b]{2}{*}{ Category } & \multirow[b]{2}{*}{ Characteristics } & \multicolumn{3}{|c|}{ Summer (August) } & \multicolumn{3}{|c|}{ Winter (January) } & \multirow{2}{*}{$T$ test $^{\mathrm{I}}$} \\
\hline & & $\begin{array}{l}\text { No. of } \\
\text { plots }\end{array}$ & Mean & $\begin{array}{c}\text { Standard } \\
\text { error }\end{array}$ & $\begin{array}{l}\text { No. of } \\
\text { plots }\end{array}$ & Mean & $\begin{array}{l}\text { Standard } \\
\text { error }\end{array}$ & \\
\hline \multirow{4}{*}{$\begin{array}{c}\text { Plant } \\
\text { diversity }\end{array}$} & $\begin{array}{l}\text { Evenness index } \\
(E)\end{array}$ & 40 & 1.2325 & 0.1669 & 40 & 1.2312 & 0.1652 & 0.006 \\
\hline & $\begin{array}{l}\text { Richness index } \\
(R)\end{array}$ & 40 & 9.450 & 0.9459 & 39 & 10.25 & 1.0447 & -0.576 \\
\hline & $\begin{array}{l}\text { Shannon-Wiener index } \\
(H)\end{array}$ & 40 & 2.3527 & 0.1573 & 40 & 2.3974 & 0.1574 & -0.201 \\
\hline & $\begin{array}{l}\text { Dominance index } \\
\text { (D) }\end{array}$ & 40 & 0.3445 & 0.0470 & 40 & 0.3470 & 0.0460 & -0.038 \\
\hline \multirow{9}{*}{$\begin{array}{l}\text { Soil physical } \\
\text { properties }\end{array}$} & $\begin{array}{l}\text { Bulk density } \\
\left(\mathrm{g} / \mathrm{cm}^{3}\right)\end{array}$ & 37 & 1.1578 & 0.0280 & 37 & 1.2421 & 0.0224 & $-2.355^{*}$ \\
\hline & $\begin{array}{c}\text { Capillary porosity } \\
(\%)\end{array}$ & 38 & 39.704 & 1.2278 & 37 & 33.880 & 0.7200 & $4.092 * *$ \\
\hline & Non-capillary porosity (\%) & 38 & 17.268 & 1.3780 & 37 & 19.519 & 0.8843 & -1.375 \\
\hline & $\begin{array}{l}\text { Total porosity } \\
(\%)\end{array}$ & 38 & 57.235 & 0.9754 & 37 & 53.303 & 0.8205 & $3.085^{*}$ \\
\hline & Natural moisture capacity (\%) & 37 & 23.478 & 1.4077 & 37 & 28.479 & 1.2284 & $-2.676^{* *}$ \\
\hline & Field moisture capacity (\%) & 38 & 31.861 & 1.1287 & 37 & 29.365 & 1.0582 & 1.613 \\
\hline & Capillary moisture capacity (\%) & 38 & 40.127 & 1.1949 & 37 & 35.951 & 1.4081 & $2.261^{*}$ \\
\hline & $\begin{array}{l}\text { Upper strata saturated permeability } \\
\qquad(\mathrm{mm} / \mathrm{mim})\end{array}$ & 38 & 10.851 & 1.5728 & 38 & 10.750 & 1.3364 & 0.049 \\
\hline & $\begin{array}{l}\text { Lower strata saturated permeability } \\
\qquad(\mathrm{mm} / \mathrm{mim})\end{array}$ & 38 & 6.8144 & 1.3948 & 38 & 6.7160 & 1.3026 & 0.052 \\
\hline \multirow{8}{*}{$\begin{array}{c}\text { Soil } \\
\text { chemical } \\
\text { properties }\end{array}$} & $\mathrm{pH}$ & 39 & 6.9923 & 0.1527 & 39 & 6.9907 & 0.1579 & 0.007 \\
\hline & $\begin{array}{l}\text { Organic matter content } \\
(\mathrm{mg} / \mathrm{kg})\end{array}$ & 39 & 43.079 & 3.2504 & 39 & 46.212 & 3.1167 & -0.696 \\
\hline & $\begin{array}{l}\text { Total nitrogen content } \\
(\mathrm{mg} / \mathrm{kg})\end{array}$ & 39 & $2,522.3$ & 202.80 & 39 & $2,631.0$ & 200.40 & -0.381 \\
\hline & Total phosphorus content (mg/kg) & 39 & 735.40 & 51.20 & 39 & 718.20 & 44.00 & 0.255 \\
\hline & $\begin{array}{l}\text { Total potassium content } \\
(\mathrm{mg} / \mathrm{kg})\end{array}$ & 39 & $1,698.20$ & 165.10 & 39 & $2,508.40$ & 271.70 & $-2.549 *$ \\
\hline & Hydrolyzed nitrogen content (mg/g) & 39 & 174.39 & 15.9940 & 39 & 167.33 & 13.6736 & 0.335 \\
\hline & Available phosphorus content $(\mathrm{mg} / \mathrm{kg})$ & 39 & 3.942 & 0.5162 & 39 & 5.7723 & 0.6947 & $-0.075^{*}$ \\
\hline & Available potassium content (mg/kg) & 39 & 95.407 & 3.7478 & 39 & 107.45 & 5.3436 & -1.845 \\
\hline
\end{tabular}

$\mathrm{I} *, * *$ indicate the significant difference at $\alpha=0.05$, and 0.01 , respectively, the same below.

\section{Comparisons of Soil Physical-Chemical Properties between Different Degrees of Rock Desertification}

Comparisons of soil physical properties between different degrees of rocky desertification were analyzed by Duncan test (Table 6), showing that there are significant differences in soil bulk density, capillary porosity, total porosity, field moisture capacity, and capillary moisture capacity between different degrees of rocky desertification. Specifically, the soil bulk density of Pot RD is significantly more than that of Mod RD and Sev RD, the capillary porosity and field moisture capacity of Pot RD significantly smaller than those of Sev RD, the total porosity of Pot RD significantly smaller than that of Mod RD, and the capillary moisture capacity of Pot RD significantly smaller than that of Sev RD.

Comparisons of soil chemical properties between different degrees of rocky desertification were analyzed by Duncan test (Table 7), showing there are significant differences in $\mathrm{pH}$, organic matter content, hydrolyzed nitrogen content, total potassium content, available 


\begin{tabular}{|c|c|c|c|c|c|c|}
\hline \multicolumn{2}{|l|}{ 世 } & \\
\hline \multirow{2}{*}{ 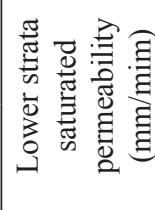 } & $\tilde{5}$ & $\sigma$ & $\pi$ & $\pi$ & $\sigma$ & $\pi$ \\
\hline & 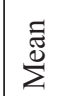 & $\underset{\sim}{\stackrel{+}{\sim}}$ & $\begin{array}{l}\overrightarrow{0} \\
\text { o. }\end{array}$ & $\stackrel{m}{\stackrel{m}{0}}$ & $\begin{array}{l}\stackrel{2}{2} \\
\infty \\
\infty\end{array}$ & $\begin{array}{l}\vec{m} \\
\stackrel{m}{n}\end{array}$ \\
\hline \multirow{2}{*}{ 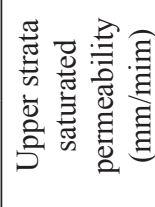 } & $\tilde{5}$ & $\pi$ & $\sigma$ & $\sigma$ & $\pi$ & $\pi$ \\
\hline & $\sum^{\frac{\Xi}{\varpi}}$ & $\begin{array}{l}\stackrel{8}{\Xi} \\
=\end{array}$ & $\begin{array}{l}\hat{\alpha} \\
\text { o. }\end{array}$ & $\hat{n}$ & $\begin{array}{l}\hat{b} \\
\stackrel{6}{2}\end{array}$ & 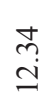 \\
\hline \multirow{2}{*}{ 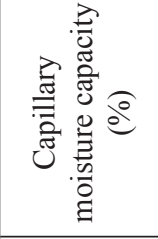 } & $\tilde{\sigma}$ & $\approx$ & $\sigma$ & $\sigma$ & $\approx$ & مـ \\
\hline & $\stackrel{\varpi}{\Sigma}_{\Sigma}^{\approx}$ & $\begin{array}{l}\forall \\
\Delta \\
\infty \\
\infty\end{array}$ & $\begin{array}{l}\vec{a} \\
\text { in }\end{array}$ & 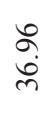 & $\begin{array}{l}\stackrel{\partial}{\circ} \\
\text { ले }\end{array}$ & $\begin{array}{l}8 \\
i \\
i f\end{array}$ \\
\hline \multirow{2}{*}{ 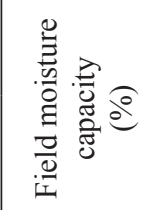 } & 哙 & ते & $\sigma$ & ते & స & م \\
\hline & $\stackrel{\Xi}{\Sigma}^{\tilde{\Xi}}$ & $\frac{\vec{n}}{m}$ & 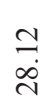 & $\frac{0}{\stackrel{1}{0}}$ & $\begin{array}{l}n \\
\dot{d} \\
\dot{d}\end{array}$ & $\begin{array}{l}\stackrel{\sim}{+} \\
\stackrel{j}{n}\end{array}$ \\
\hline \multirow{2}{*}{ 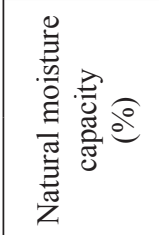 } & 芯 & $\approx$ & $\sigma$ & $\sigma$ & $\pi$ & $\sigma$ \\
\hline & $\stackrel{\Xi}{\Sigma}^{\Xi}$ & $\begin{array}{l}\hat{n} \\
\infty \\
i\end{array}$ & $\begin{array}{l}\stackrel{2}{2} \\
\text { ते }\end{array}$ & $\begin{array}{l}n \\
n \\
\dot{N}\end{array}$ & 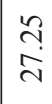 & $\begin{array}{l}\text { ț } \\
\text { d }\end{array}$ \\
\hline \multirow{2}{*}{ 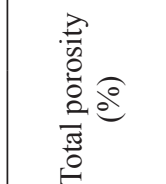 } & 㔚 & ते & $\pi$ & ते & مـ & बे \\
\hline & $\stackrel{\Xi}{\Sigma}^{\Xi}$ & $\begin{array}{l}\overrightarrow{0} \\
\stackrel{0}{0} \\
\stackrel{n}{n}\end{array}$ & $\begin{array}{l}0 \\
n \\
\sim \\
n\end{array}$ & $\frac{\infty}{i n}$ & \begin{tabular}{|l}
$\infty$ \\
\multirow{1}{*}{} \\
$i n$
\end{tabular} & 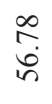 \\
\hline \multirow{2}{*}{ 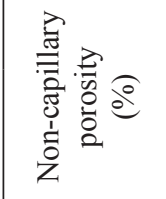 } & 羟 & $\sigma$ & $\sigma$ & $\sigma$ & $\sigma$ & $\sigma$ \\
\hline & 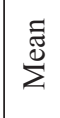 & $\begin{array}{l}\hat{\sigma} \\
\infty \\
-\infty\end{array}$ & $\begin{array}{l}\widetilde{\alpha} \\
\stackrel{\infty}{-}\end{array}$ & $\begin{array}{l} \pm \\
\infty \\
\infty \\
\infty\end{array}$ & $\begin{array}{l}\stackrel{g}{0} \\
\end{array}$ & 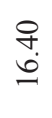 \\
\hline \multirow{2}{*}{ 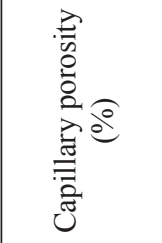 } & 放 & ते & $\sigma$ & ते & ते & مـ \\
\hline & $\stackrel{\Xi}{\Sigma}^{\approx}$ & $\underset{m}{\stackrel{m}{\infty}}$ & $\vec{i}$ & 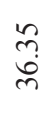 & 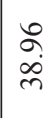 & $\begin{array}{l}\Omega \\
\dot{q} \\
\stackrel{q}{0}\end{array}$ \\
\hline \multirow{2}{*}{ 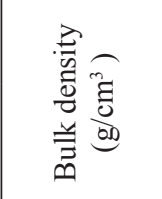 } & $\begin{array}{l}\tilde{\Sigma} \\
\tilde{\zeta}\end{array}$ & ते & $\sigma$ & ब & 0 & مـ \\
\hline & $\stackrel{\Xi}{\Sigma}^{\Xi}$ & $\underset{\text { तె }}{ }$ & $\begin{array}{l}\vec{F} \\
\underset{\sim}{\infty}\end{array}$ & $\stackrel{\infty}{\infty}$ & 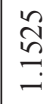 & $\begin{array}{l}\widehat{\infty} \\
\stackrel{\sim}{\rightarrow}\end{array}$ \\
\hline \multicolumn{2}{|l|}{ 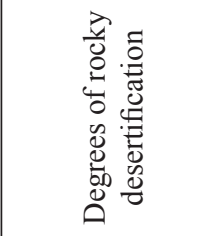 } & $\bar{z}$ & 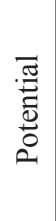 & $\frac{\vec{t}}{\frac{\overrightarrow{b o}}{\bar{n}}}$ & 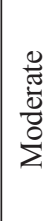 & 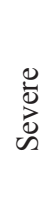 \\
\hline
\end{tabular}

\begin{tabular}{|c|c|c|c|c|c|c|}
\hline \multicolumn{2}{|l|}{$\begin{array}{l}\vec{y} \\
\underline{\underline{y}}\end{array}$} & \multicolumn{5}{|c|}{$*$} \\
\hline \multirow{2}{*}{ 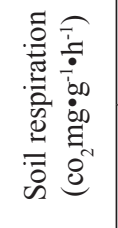 } & 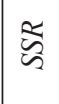 & $\pi$ & م & م & م & مـ \\
\hline & $\sum^{\tilde{\Xi}}$ & $\begin{array}{l}n \\
0 \\
0 \\
0 \\
0\end{array}$ & $\stackrel{\circ}{\stackrel{2}{7}}$ & 売 & $\mid \begin{array}{l}\infty \\
\infty \\
o \\
0\end{array}$ & \begin{tabular}{l}
0 \\
\multirow{0}{0}{} \\
0
\end{tabular} \\
\hline \multirow{2}{*}{ 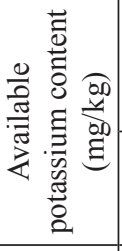 } & 怗 & $\sigma$ & $\sigma$ & $\sigma$ & $\sigma$ & $\sigma$ \\
\hline & $\stackrel{\varpi}{\Sigma}^{\approx}$ & $\overrightarrow{0}$ & $\ddot{\circ}$ & $\begin{array}{l}\text { ô } \\
\text { aू }\end{array}$ & ô. & $\begin{array}{l}- \\
\infty \\
\&\end{array}$ \\
\hline \multirow{2}{*}{ 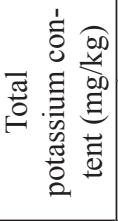 } & 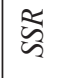 & $\pi$ & ๘ & م & 0 & م \\
\hline & $\sum_{\tilde{\Xi}}^{\approx}$ & 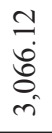 & $\begin{array}{l}\tilde{\jmath} \\
\stackrel{\varrho}{\vdots} \\
i\end{array}$ & 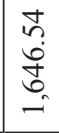 & 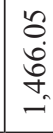 & 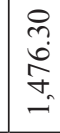 \\
\hline \multirow{2}{*}{ 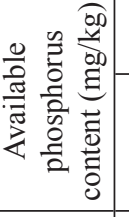 } & $\widetilde{\hbar}$ & $\sigma$ & مـ & ఉి & డి & $\sigma$ \\
\hline & $\sum_{\tilde{\Xi}}^{\tilde{\Xi}}$ & $\stackrel{n}{m}$ & $\hat{n}$ & $\begin{array}{l}\infty \\
\infty \\
0 \\
\dot{n}\end{array}$ & $\begin{array}{l}\tilde{\sigma} \\
\tilde{\sigma}\end{array}$ & 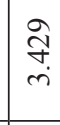 \\
\hline \multirow{2}{*}{ 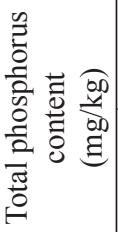 } & 㻤 & $\pi$ & $\sigma$ & $\sigma$ & $\sigma$ & $\sigma$ \\
\hline & $\sum_{\text {हू }}^{\text {हू }}$ & 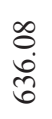 & 年 & $\begin{array}{l}\hat{\sigma} \\
\dot{\tilde{D}} \\
\infty\end{array}$ & $\begin{array}{l}\mathcal{1} \\
\infty \\
\stackrel{+}{+} \\
\stackrel{1}{1}\end{array}$ & $\frac{n}{\grave{\xi}}$ \\
\hline \multirow{2}{*}{ 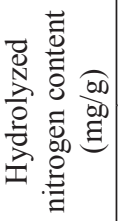 } & 芯 & ש & مـ & $\ddot{\pi}$ & 0 & त \\
\hline & $\stackrel{\varpi}{\Sigma}_{\Sigma}^{\Xi}$ & $\frac{\mathfrak{c}}{\stackrel{\sim}{\vec{d}}}$ & $\begin{array}{l}\Omega \\
\grave{I} \\
\end{array}$ & 官 & $\begin{array}{l}\tilde{\sigma} \\
\tilde{N} \\
\text { J }\end{array}$ & $\begin{array}{l}n \\
f \\
\infty \\
\infty \\
-\end{array}$ \\
\hline \multirow{2}{*}{ 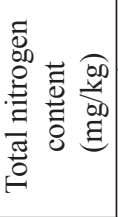 } & 敌 & $\sigma$ & $\sigma$ & $\sigma$ & $\sigma$ & $\sigma$ \\
\hline & $\stackrel{\Xi}{\Sigma}^{\Xi}$ & 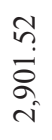 & $\begin{array}{l}f \\
f \\
d \\
d \\
\text { di }\end{array}$ & $\begin{array}{l}n \\
+\infty \\
\infty \\
\infty \\
\infty \\
i\end{array}$ & $\begin{array}{l}n \\
\tilde{c} \\
\tilde{n} \\
\text { in }\end{array}$ & 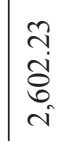 \\
\hline \multirow{2}{*}{ 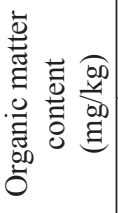 } & $\tilde{\Sigma}$ & $\sigma$ & مـ & ह & च & 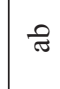 \\
\hline & 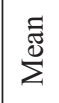 & $\underset{i}{\stackrel{+}{i}}$ & 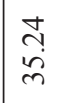 & $\begin{array}{l}\infty \\
\stackrel{f}{f} \\
\stackrel{f}{f}\end{array}$ & \begin{tabular}{|l}
$\infty$ \\
\multirow{f}{*}{} \\
$\dot{f}$
\end{tabular} & $\begin{array}{l}\frac{7}{+} \\
\dot{g}\end{array}$ \\
\hline \multirow{2}{*}{ 壳 } & $\widetilde{\hbar}$ & $\approx$ & مـ & م & مـ & م \\
\hline & $\sum_{\Sigma}^{\Xi \Xi}$ & $\frac{\infty}{0}$ & 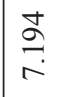 & $\underset{\vec{g}}{\stackrel{\sigma}{r}}$ & 尔 & ఫे \\
\hline \multicolumn{2}{|c|}{ 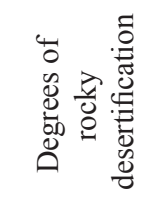 } & $\bar{z}$ & 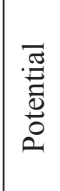 & $\begin{array}{l}\frac{\vec{y}}{.00} \\
\vec{m}\end{array}$ & $\begin{array}{l}\frac{0}{\pi} \frac{\pi}{\frac{\pi}{0}} \\
\frac{0}{0}\end{array}$ & 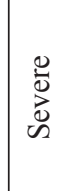 \\
\hline
\end{tabular}


phosphorus content, and soil respiration between degrees of rocky desertification. Specifically, the $\mathrm{pH}$ of Nil RD (mean of 6.182) is significantly smaller than that of Pot RD, Sli RD, Mod RD, and Sev RD; and the organic matter content of Nil RD is significantly more than that of Pot RD; the hydrolyzed nitrogen content of Pot RD is significantly smaller than that of Nil, Sli, and Mod RD; the available phosphorus content of Pot RD is significantly more than that of Nil and Sev RD; the total potassium content of Nil RD, no significant difference with that of Pot RD, is significantly more than that of Sli, Mod, and Sev RD; the soil respiration of Nil RD is significantly more than that of Pot, Sli, Mod and Sev RD.

\section{Seasonal Dynamic of Soil Physical-Chemical Properties in Rocky Desertification Ecosystem}

Comparisons of soil physical-chemical properties of rocky desertification ecosystem determined in January and August, respectively, from 2008 to 2012, were analyzed by $T$ test (Table 5). Results show there are significant differences of soil bulk density, total porosity, capillary porosity, capillary moisture capacity, natural moisture capacity, total potassium content, and available phosphorus content between January and August. Soil bulk density of rocky desertification in summer (August) is significantly smaller than winter (January), on the contrary, soil total porosity and capillary moisture capacity in summer are significantly more than winter. There are extremely significant $(\alpha=0.01)$ differences of capillary porosity and natural moisture capacity between summer and winter, that is, capillary porosity of summer is extremely significantly more than that of winter, and natural moisture capacity of summer extremely significantly smaller than that of winter. Besides, the total potassium and available phosphorus content among soil chemical properties of summer are significantly smaller than those of winter.

\section{Correlation of Plant Diversity and Soil Physical-Chemical Properties in Rocky Desertification Ecosystem}

Correlation analysis of soil physical-chemical properties and plant diversity show there are significant correlations between soil physical-chemical properties and plant diversity in rocky desertification ecosystem

Table 8. Correlat ion of plant diversity and soil physical-chemical factors in rocky desertification ecosystem.

\begin{tabular}{|c|c|c|c|c|}
\hline Soil physical-chemical factors & $\begin{array}{c}\text { Richness index } \\
(R)\end{array}$ & $\begin{array}{c}\text { Shannon-Wiener index } \\
(H)\end{array}$ & $\begin{array}{l}\text { Evenness } \\
\text { index }(E)\end{array}$ & $\begin{array}{c}\text { Dominance index } \\
(D)\end{array}$ \\
\hline $\begin{array}{l}\text { Bulk density } \\
\qquad\left(\mathrm{g} / \mathrm{cm}^{3}\right)\end{array}$ & $-0.454^{* * 1}$ & $-0.408^{* *}$ & -0.013 & 0.174 \\
\hline $\begin{array}{c}\text { Capillary porosity } \\
(\%)\end{array}$ & 0.157 & 0.211 & -0.114 & $-0.335^{* *}$ \\
\hline Non- capillary porosity (\%) & 0.136 & 0.043 & 0.134 & $0.251^{*}$ \\
\hline $\begin{array}{c}\text { Total porosity } \\
(\%)\end{array}$ & $0.346^{* *}$ & $0.311^{* *}$ & 0.009 & -0.104 \\
\hline Natural moisture capacity (\%) & 0.179 & -0.014 & 0.152 & 0.052 \\
\hline Field moisture capacity (\%) & $0.518^{* *}$ & $0.516^{* *}$ & 0.170 & $-0.266^{*}$ \\
\hline Capillary moisture capacity (\%) & $0.499^{* *}$ & $0.532^{* *}$ & -0.001 & -0.193 \\
\hline Upper strata saturated permeability (mm/mim) & $0.365^{* *}$ & 0.214 & -0.063 & 0.170 \\
\hline Lower strata saturated permeability $(\mathrm{mm} / \mathrm{mim})$ & 0.223 & -0.008 & -0.171 & $0.359^{* *}$ \\
\hline $\mathrm{pH}$ & $0.248^{*}$ & $0.398^{* *}$ & $-0.541^{* *}$ & $-0.284^{*}$ \\
\hline Organic matter content (mg/kg) & $0.635^{* *}$ & $0.349^{* *}$ & 0.143 & -0.092 \\
\hline $\begin{array}{l}\text { Total nitrogen content } \\
\qquad(\mathrm{g} / \mathrm{kg})\end{array}$ & $0.719^{* *}$ & $0.572^{* *}$ & -0.088 & $-0.262^{*}$ \\
\hline Total phosphorus content (g/kg) & $0.306^{* *}$ & 0.213 & $-0.340^{*}$ & $-0.240^{*}$ \\
\hline Total potassium content $(\mathrm{g} / \mathrm{kg})$ & -0.018 & -0.199 & $0.396^{* *}$ & 0.175 \\
\hline Hydrolyzed nitrogen content (mg/g) & $0.759^{* *}$ & $0.385^{* *}$ & -0.011 & $-0.226^{*}$ \\
\hline Available phosphorus content (mg/kg) & 0.092 & $0.247^{*}$ & $-0.309^{* *}$ & -0.085 \\
\hline Available potassium content (mg/kg) & $0.260^{*}$ & $0.253^{*}$ & 0.127 & 0.015 \\
\hline Soil respiration $\left(\mathrm{Co}_{2} \mathrm{mg} \cdot \mathrm{g}^{-1} \cdot \mathrm{h}^{-1}\right)$ & $0.405^{*}$ & -0.107 & $0.327^{*}$ & -0.029 \\
\hline
\end{tabular}

$\mathrm{I} *, * *$ indicate the significant correlation at $\alpha=0.05$, and 0.01 , respectively. 
(Table 8). Specifically, the richness index is extremely significant negative correlated with soil bulk density, significantly positive correlated with $\mathrm{pH}$, available potassium content, and soil respiration, and extremely significant positive correlated with total porosity, field moisture capacity, capillary moisture capacity, upper strata saturated permeability, organic matter content, total nitrogen content, total phosphorus content, and hydrolyzed nitrogen content. The Shannon-Wiener index is extremely significant negative correlated with soil bulk density, significant positive correlated with available phosphorus and available potassium content, and extremely significant positive correlated with total porosity, field moisture capacity, capillary moisture capacity, $\mathrm{pH}$, organic matter content, total nitrogen content, and hydrolyzed nitrogen content. The evenness index is significant negative correlated with total phosphorus content, extremely significant negative correlated with $\mathrm{pH}$ and available phosphorus content, significant positive correlated with soil respiration, and extremely significant positive correlated with total potassium content. The dominance index is significant negative correlated with field moisture capacity, $\mathrm{pH}$, total nitrogen content, and total phosphorus content, extremely significant negative correlated with capillary porosity, significant positive correlated with non-capillary porosity, and extremely significant positive correlated with lower strata saturated permeability.

\section{Principal Component Analysis of Rocky Desertification}

Principal component analysis of karst rocky desertification based on the 22 indicators of plant diversity indices and soil physical-chemical properties was conducted (Table 9), and the eigenvalue, percentage and cumulative percentage were filled in table 9. Results show the cumulative percentage of components 1 and 2 reach $81.39 \%$, showing the component 1 and 2 hold majority information on rocky desertification of the 22 indicators and can be selected as the bases for evaluating the rocky desertification ecosystem. In the principle component 1 , the weight coefficient of organic matter content, evenness index, total nitrogen content, total potassium content, Shannon-Wiener index, hydrolyzed nitrogen content, and available potassium content is high, all more than 0.90 , showing the principle component 1 mainly represent the information on rocky desertification of organic matter, evenness index, nitrogen content, potassium content, and ShannonWiener index. In the principle component 2, the weight coefficient of $\mathrm{pH}$, capillary porosity, non-capillary porosity, and lower strata saturated permeability is high, showing the principle component 2 mainly represent the information on rocky desertification of $\mathrm{pH}$, porosity, and permeability.
Table 9. Principal component analysis of rocky desertification based on plant diversity and soil physical-chemical properties.

\begin{tabular}{|c|c|c|}
\hline \multirow{2}{*}{ Characteristics } & \multicolumn{2}{|c|}{ Components } \\
\hline & 1 & 2 \\
\hline Organic matter content & 0.985 & -0.112 \\
\hline Evenness index & 0.964 & 0.239 \\
\hline Total nitrogen content & 0.958 & -0.181 \\
\hline Total potassium content & 0.957 & 0.242 \\
\hline Shannon-Wiener index & 0.950 & -0.223 \\
\hline Hydrolyzed nitrogen content & 0.946 & -0.324 \\
\hline Available potassium content & 0.938 & 0.252 \\
\hline Richness index & 0.893 & 0.191 \\
\hline Field moisture capacity & 0.892 & 0.341 \\
\hline Soil respiration & 0.862 & 0.194 \\
\hline Natural moisture capacity & 0.832 & -0.315 \\
\hline Total phosphorus content & 0.851 & -0.144 \\
\hline Capillary moisture capacity & 0.794 & -0.343 \\
\hline Upper strata saturated permeability & 0.696 & 0.382 \\
\hline Bulk density & -0.641 & -0.230 \\
\hline Lower strata saturated permeability & -0.641 & -0.716 \\
\hline Available phosphorus content & 0.592 & 0.601 \\
\hline Dominance index & -0.555 & 0.606 \\
\hline Capillary porosity & 0.545 & -0.817 \\
\hline Non-capillary porosity & -0.435 & 0.720 \\
\hline Total porosity & -0.169 & -0.606 \\
\hline $\mathrm{pH}$ & -0.130 & 0.904 \\
\hline Eigenvalue & 13.289 & 4.617 \\
\hline Percentage $(\%)$ & 60.406 & 20.987 \\
\hline Cumulative percentage $(\%)$ & 60.406 & 81.392 \\
\hline
\end{tabular}

The scatter diagram of 22 indictors and 5 typical degrees of rocky desertification can be seen in Fig. 5. Results show that the evenness and richness index of plant diversity is obvious correlated with soil physical-chemical properties of available phosphorus content, upper strata saturated permeability, field moisture capacity, total potassium content, available potassium content, and soil respiration, together representing Nil RD. The dominance index of plant diversity and soil physical-chemical properties of $\mathrm{pH}$ and non-capillary porosity are more correlative to Pot and Sli RD. The Shannon-Wiener index of plant diversity and soil physical-chemical properties of total porosity, lower strata saturated permeability are more correlative to Mod RD. There are obvious correlation of total phosphorus content, organic matter content, total nitrogen content, bulk density, natural moisture capacity, hydrolyzed nitrogen, and capillary moisture capacity, together representing Sev RD. 


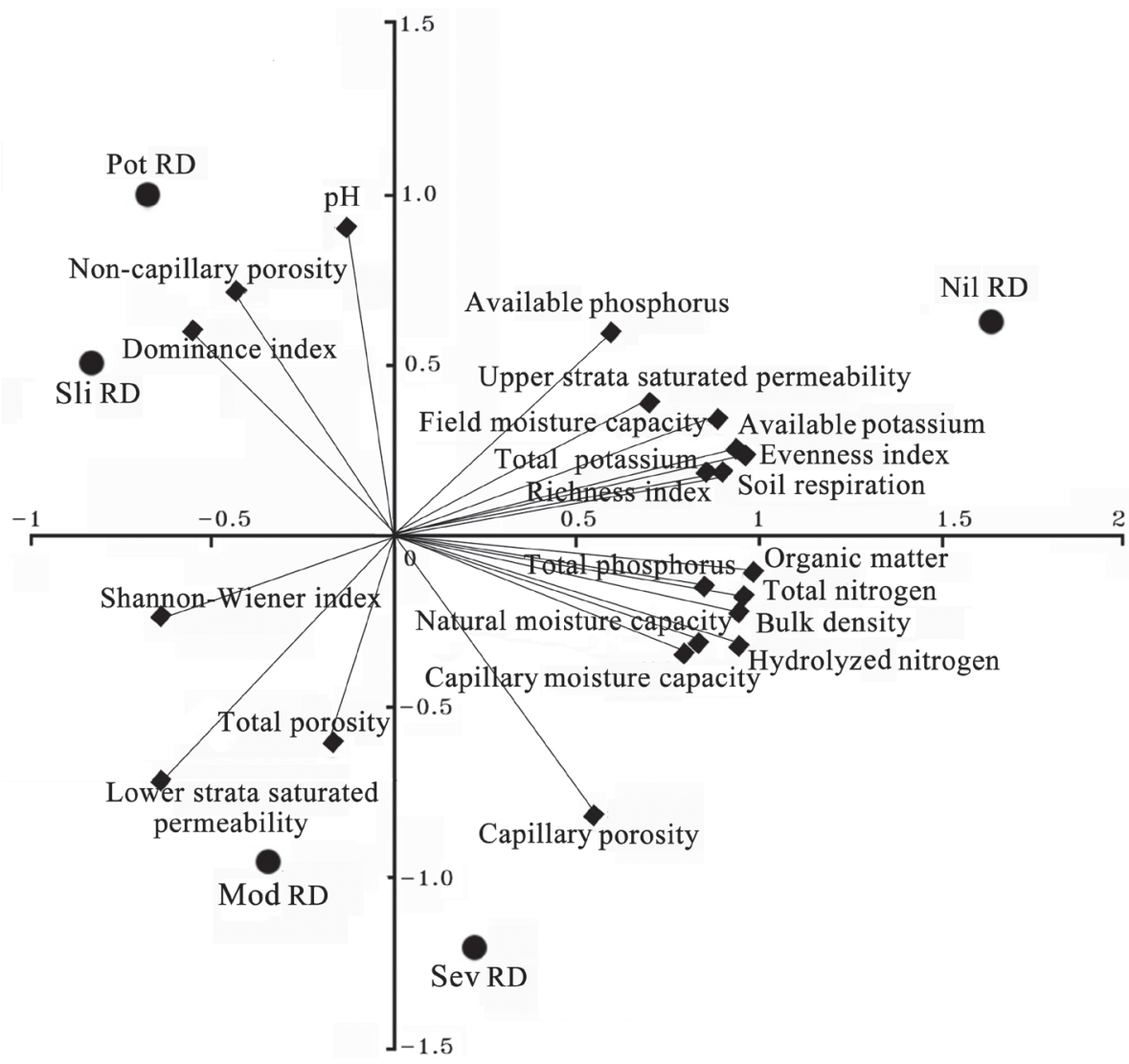

Fig. 5. Scatter diagram of principal component analysis of karst rocky desertification.

\section{Discussion}

\section{Patterns and Dynamics of Plant Diversity in Karst Rocky Desertification Ecosystem}

In karst rocky desertification ecosystem, the landscape heterogeneity is very high with high percentage of exposed rock, and the soil is rare and dry. So the plant distributed in rocky desertification is lithophilous, calciphilous, and drought-tolerant, and have massive and strong root system. All these result in the vegetation structure of karst rocky desertification ecosystem is very different with general zonal distribution [29]. In this study, the four indices of plant diversity all are very low were observed, showing the plant ecosystem of rocky desertification has been destroyed seriously, and is at a very low stage of restoration succession. The herbaceous layer only is composed of 14 species belonging to 14 genera and 9 families, the tree layer composed of 13 species belonging to 12 genera and 10 families, and the majority of families distributed only have one species lived, all which show there are remarkable ecological stresses on plant distribution and growth in rocky desertification ecosystem. In these taxa surveyed, only families of Asteraceae, Rosaceae, Poaceae, Caprifoliaceae, and Euphorbiaceae have more than one species lived, showing these taxa have better adaptability in rock desertification ecosystem. Results also show there are significant differences in the adaptability of species distributed in rocky desertification ecosystem among different degrees of rocky desertification. All these offer an important basis for the selection of pioneer species and the application of control techniques in the rehabilitation of rocky desertification.

Results show that with increased interference of rocky desertification from nil, potential, slight, moderate to severe degree, the plant diversity appears obviously change, for example, species number is more few, living form further simplify, importance value ratio of dominant species is more high, and the structure ratio of 1 family 1 genus 1 species 1 living form is more few, all which confirm that external interference seriously influence the process of phytocommunity succession through grievously destroying the species composition and structure $[10,23]$. The species succession also has remarkable responses to the degeneration, and along the order form nil to severe rocky desertification, the species succession is stable species $\rightarrow$ secondary stable species $\rightarrow$ transitional species $\rightarrow$ secondary pioneer species $\rightarrow$ pioneer species. Thus, in the artificial rehabilitation of degenerative karst plant ecosystem, different control measures should be carried out for the different degrees of rocky desertification. Specifically, for the intact original karst vegetation, the protect measures should be carried out to make it avoiding the interferences of human activities; For the degenerating rocky desertification ecosystem, mature 
plant individuals of succession top should be selected in the vegetation rehabilitation. For the restoring rocky desertification ecosystem, the secondary forest should be pruned properly to keep suitable density, benefiting to the quick recover of sexual reproduction chain and good growth of individuals.

\section{Response of Soil Physicochemical Properties to Rocky Desertification Succession}

Pedogenesis is a very complex process affected by many factors such as climate, vegetation, landform, parent rock, and so on. Moreover, soil constantly changes with the succession of plant vegetation [30]. Generally, the positive succession of plant community is the process of soil nutrient accumulation and soil physical property improvement, and the negative succession is the process of soil degeneration [30]. For a long time, soil degradation is believed to increase with increased degree of rocky desertification, and soil degradation in Sev RD is considered as the most serious [2, 10, 23, 31]. However, results of the present study reveal this assumption is false. Both physical and chemical properties do not always degenerate with increased degree of rocky desertification. Instead, properties initially degenerate and then improve. This result is reported for the first time and has extremely important value in the rehabilitation of the rocky desertification ecosystem. In the control of karst rocky desertification, the vegetation of Sev RD has long been thought to be rehabilitated only by the measure of closed forest, and artificial afforestation is believed to be impossible in Sev RD habitats [2]. However, the present results show the soil quality of Sev RD is better than that of Pot RD or Sli RD, and vegetation rehabilitation can be completely carried out through artificial afforestation, which can be well supported by many control practices [2].

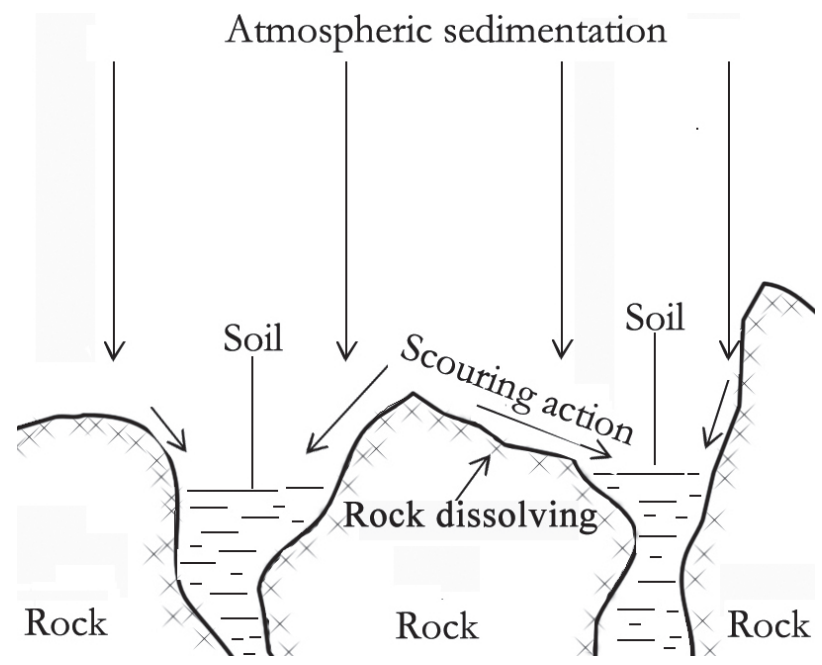

Fig. 6. The action of soil nutrients collected by exposed rocks in rocky desertification ecosystem.
The observed results should be attributed to the action of soil nutrients collected by exposed rocks in the rocky desertification ecosystem. The significant action processes are that the atmospheric sedimentation and dissolution of rocks on the surface of exposed rocks are scoured into surrounding soils (Fig. 6). With increased degree of rocky desertification, the action process remarkably increases and soil erosion decreases because of the decrease in soil that can be washed away. In Sev RD, on one hand, soil erosion is weak because of the limited amount of soil that can be washed away, which in turn results in limited soil nutrient loss; on the other hand, the action process of soil nutrients collected by exposed rocks is very strong. Consequently, the soil nutrient and physicochemical properties of degenerative soil are improved (Fig. 7).

\section{Evaluation Index System of Karst Rocky Desertification}

The evaluation of ecosystem health is an emerging and important study field [32]. At present, the researches of ecosystem health evaluation mainly focus on such ecosystems of forest, wetland, river, farmland, and city [33]. As well known, the process, pattern, and function of karst ecosystem all are obviously different with other ecosystems [34, 35]. But so far, there are seriously short of evaluation studies on karst ecosystem health. Especially, for the karst rocky desertification ecosystem, the relative research basically is zero [31,33], although it is very urgent to found the technical system of survey, evaluation and early warning for rocky desertification in

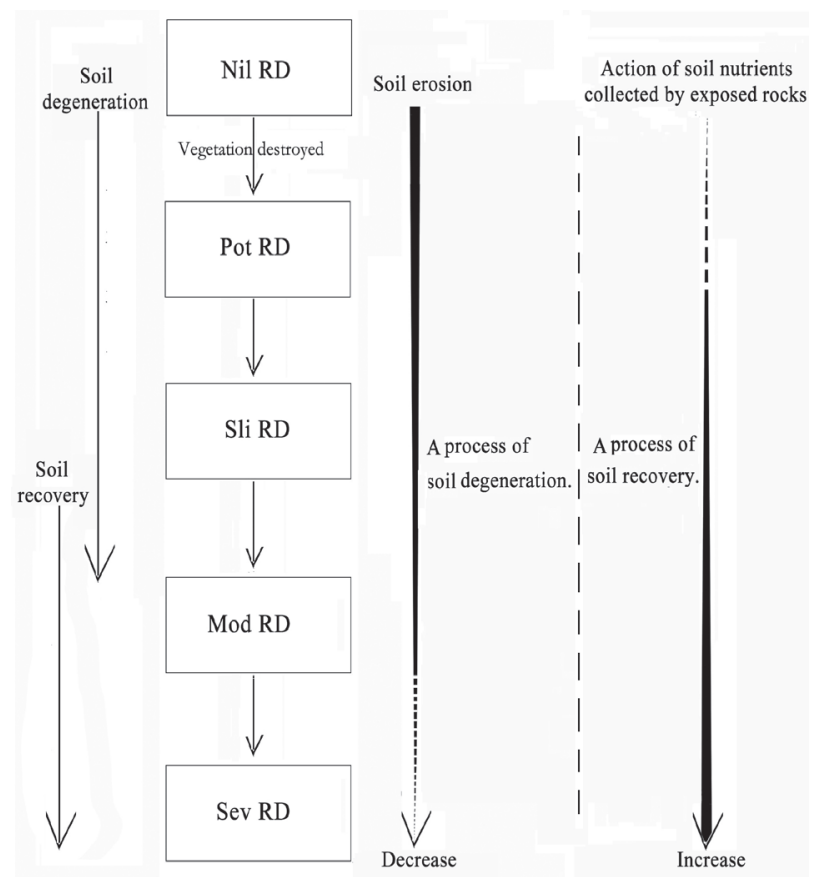

Fig. 7. The evolution process and response mechanism of soil physical-chemical properties along with the rocky desertification succession. 
karst ecosystem $[2,5,7,11,16]$. So in this study, based on the survey and analyses of plant diversity and soil physical-chemical properties, the evaluation technique system of rocky desertification were conducted.

Results show that the plant diversity and soil physical-chemical properties have obvious responses to the degenerative degree of rocky desertification both in scales of experiment site and sample plot, but in different scale, the responses are remarkably different. In the scale of experiment site, the plant diversity indices of evenness, dominance, and Shannon-Wiener and soil physical-chemical properties of capillary porosity, noncapillary porosity, upper strata saturated permeability, lower strata saturated permeability, $\mathrm{pH}$, total nitrogen content, and total phosphorus content have an linear responses to the degrees of rocky desertification, suggesting that these indices and factors can evaluate the degenerative degree of rocky desertification in big scale. In the scale of sample plot, only the evenness index of plant diversity can reflect the degrees of rocky desertification, the other three indices basically can not reflect the degrees of rocky desertification, which can be attributed to that the sample plots are easily interfered by the strong human activities. The evenness index of plant diversity and soil physicalchemical factors of total phosphorus content, $\mathrm{pH}$, available phosphorus content, soil respiration, and total potassium content should be the indices and factors of evaluating the degenerative degree of rocky desertification in patch scale. Results offer important bases for the further researches of degeneration and restoration mechanism of rocky desertification ecosystem, and have important value in the application of vegetation rehabilitation techniques for the control of rocky desertification.

\section{Conclusions}

The vegetation of rocky desertification ecosystems proved to be very simple with an extremely low species richness index. With increased degree of rocky desertification, there are remarkable changes in plant diversity: species number declines; the ratio of dominant species importance value is higher; species composition becomes more disorder. There are significant differences in plant diversity indices among different degrees of rocky desertification. On the large scale, evenness and dominance indices of plant diversity increase and the Shannon-Wiener index decreases along the increased gradient of desertification. There were also significant differences in soil physical-chemical properties among the five degrees of desertification. Both physical and chemical properties do not always degenerate with increased degree of rocky desertification. Instead, properties initially degenerate and then improve. And there was a remarkable correlation between soil physical-chemical properties and plant diversity. All these offer bases to clarify the evolution law and formation mechanism of plant diversity and soil physical-chemical properties in karst rocky desertification ecosystem, and have extremely important value in the rehabilitation of the karst rocky desertification ecosystem.

\section{Author Contributions}

Conceptualization, L.W. and M.S.; methodology, L.W. and M.S.; formal analysis, L.W., S.L. and J.W.; data curation, L.W., S.L. and J.W.; writing-original draft preparation, L.W. and J.W.; writing-review and editing, S.L. and M.S.; project administration, M.S.; funding acquisition, M.S. All authors have read and agreed to the published version of the manuscript.

\section{Acknowledgments}

This work was supported by the National Natural Science Foundation of China (31660136), the Key Project of Guizhou Science and Technology Fund (Qiankehe Jichu [2016]1414), the Support Plan for Excellent Young Science and Technology talents of Guizhou Province (No. Qiankehe Pingtai Rencai [2017]5638), the Project of Guizhou Science and Technology Plan (No. Qiankehe Pingtai Rencai [2017]5726), and the Support Plan for Science and Technology Top-notch Talents of Guizhou Higher Education Institutions (Qianjiaohe KY zi [2016]064).

\section{Conflicts of Interest}

The authors declare no conflict of interest.

\section{References}

1. LEGRAND H.E. Hydrological and ecological problems of karst regions: hydrological actions on limestone regions cause distinctive ecological problems. Science, 179, 859, 1973.

2. ZHANG Y.H., XU X.L., LI Z.W., LIU M.X., XU C.H., ZHANG R.F., LUO W. Effects of vegetation restoration on soil quality in degraded karst landscapes of southwest China. Sci. Total Environ., 650, 2657, 2019.

3. ZHENG D. Research of China ecologic and geographical district system; Commercial Press: Beijing, China, 89, 2008 [In Chinese].

4. ZHANG X.B., WANG S.J., CAO J.H. Characteristics of water loss and soil erosion and some scientific problems on karst rocky desertification in southwest China karst area. Carsologica Sin., 29, 274, 2010.

5. JIANG Z.C., LIAN Y.Q., QIN X.Q. Rocky desertification in Southwest China: Impacts, causes, and restoration. Earth Sci. Rev., 132, 1, 2014.

6. PENG J., XU Y.Q., ZHANG R., XIONG K.N., LAN A.J. Soil erosion monitoring and its implication in a limestone land suffering from rocky desertification in the Huajiang 
Canyon, Guizhou, Southwest China. Environ Earth Sci., 69, 831, 2013.

7. SWEETING M.M. Karst in China, its geomorphology and environment; Springer-Verlag: Berlin, Germany, 61, 1995.

8. XU E.Q., ZHANG H.Q., LI M.X. Mining spatial information to investigate the evolution of karst rocky desertification and its human driving forces in Changshun, China. Sci. Total Environ., 458-460, 419, 2013.

9. SHENG M.Y., XIONG K.N., WANG L.J., LI X.N., LI R., TIAN X.J. Response of soil physical and chemical properties to rocky desertification succession in South China Karst. Carbonates Evaporites, 33, 1, 2018.

10. LI Y.B., SHAO J.G., BAI X.Y. The relations between land use and karst rocky desertification in a typical karst area, China. Environ. Geol., 57, 621, 2009.

11. XIONG K.N., LI P., ZHOU Z.F. Remote sensing of karst rocky desertification - a typical research of GIS taking Guizhou Province as an example; Geology Publishing House: Beijing, China, 101, 2002 [In Chinese].

12. DU Y.X., PAN G.X., LI L.Q. Leaf N/P ratio and nutrient reuse between dominant species and stands: predicting phosphorus deficiencies in karst ecosystems, southwestern China. Environ. Earth. Sci., 64, 299, 2011.

13. XIAO K.C., HE T.G., CHEN H., PENG W.X., SONG T.Q., WANG K.L., LI D.J. Impacts of vegetation restoration strategies on soil organic carbon and nitrogen dynamics in a karst area, Southwest China. Ecol. Eng., 101, 247, 2017.

14. DUNCAN G.R. Biodiversity: endangered and in demand. Nature, 480, 101, 2011.

15. 15. MIDGLEY G.F. Biodiversity and ecosystem function. Science, 335(6065), 174, 2012.

16. CAI Y.L. Preliminary research on ecological reconstruction in karst mountain poverty areas of southwest China. Adv. Earth Sci., 11, 602, 1996.

17. KOBZA R.M., TREXLER J.C., LOFTUS W.F. Community structure of fishes inhabiting aquatic refuges in a threatened karst wetland and its implications for ecosystem management. Biol. Conserv., 116, 153, 2004.

18. GUO K., LIU C.C., DONG M. Ecological adaptation of plants and control of rocky-desertification on karst region of Southwest China. Chinese J. Plant Ecol., 35, 991, 2011.

19. HE X.Y., WANG K.L., ZHANG W., CHEN Z.H., ZHU Y.G., CHEN H.S. Positive correlation between soil bacterial metabolic and plant species diversity and bacterial and fungal diversity in a vegetation succession on Karst. Plant Soil, 307, 123, 2008.

20. ZHANG X.B., BAI X.Y., HE X.B. Soil creeping in the weathering crust of carbonate rocksand underground soil losses in the karst mountain areas of southwest china. Carbonate Evaporite, 26, 149, 2011.

21. LIU C.Q., LIANG Y.C., LI S.L. Researches on biogeochemical processes and nutrient cycling in karstic ecological systems, southwest China: a review. Earth Sci. Front., 16, 1, 2009.

22. HECTOR E.M., ROBERT C.G., MICHAEL F.A., JUAN J.J.O., SAID R.C. The importance of limestone bedrock and dissolution karst features on tree root distribution in northern Yucatán, México. Plant Soil, 362, 37, 2013.

23. LUO G.J., LI Y.B., WANG S.J. Comparison of ecological significance of landscape diversity changes in karst mountains: a case study of 4 typical karst area in Guizhou Province. Acta Ecologica Sin., 31, 3883, 2011.

24. LIU G.S. Soil physical and chemical analysis and description of profile; China Standard Press: Beijing, China, 32, 1996 [In Chinese].

25. CHEN H.S., ZHANG W., WANG K., HOU Y. Soil organic carbon and total nitrogen as affected by land use types in karst and non-karst areas of northwest Guangxi, China. J. Sci. Food. Agric., 92, 1086, 2012.

26. LI D.J., WEN L., YANG L.Q., LUO P., XIAO K.C., CHEN H., ZHANG W., HE X.Y., CHEN H.S., WANG K.L. Dynamics of soil organic carbon and nitrogen following agricultural abandonment in a karst region. J. Geophys. Res-biogeo., 122, 230, 2016.

27. WANG L.J., WANG P., SHENG M.Y., TIAN J. Ecological stoichiometry and environmental influencing factors of soil nutrients in the karst rocky desertification ecosystem, southwest China. Glob. Ecol. Conserv., e00449, 2018.

28. DU R.Q. Biostatistics; Higher Education Press: Beijing, China, 28, 2009 [In Chinese].

29. LIAO H.K., LONG J., LI J. Soil organic carbon associated in size-fractions as affected by different land uses in karst region of Guizhou, Southwest China. Environ. Earth Sci., 74, 6877, 2016.

30. KANG B., LIU S.R., CAI, D.X., LU L.H., HE R.M., GAO Y.X., DI W.Z. Soil physical and chemical characteristics under different vegetation restoration patterns in China south subtropical area. Chinese J. Appl. Ecol., 21, 2479, 2010.

31. LI L.Q., WANG D., LIU X.Y., ZHANG B., LIU Y.Z., XIE T., DU Y.X., PAN G.X. Soil organic carbon fractions and microbial community and functions under changes in vegetation: a case of vegetation succession in karst forest. Environ. Earth Sci., 71, 3727, 2014.

32. LIU S.J., ZHANG W., WANG K.L., PAN F.J., YANG S., SHU S.Y. Factors controlling accumulation of soil organic carbon along vegetation succession in a typical karst region in Southwest China. Sci. Total Environ., 521-522, $52,2015$.

33. LU X.Q., TODA H., DING F.J., FANG S.Z., YANG W.X., XU H.G. Effect of vegetation types on chemical and biological properties of soils of karst ecosystems. Eur. J. Soil Biol., 61, 49, 2014.

34. ZHANG W., ZHAO J., PAN F.J., LI D.J. Changes in nitrogen and phosphorus limitation during secondary succession in a karst region in southwest China. Plant Soil, 391 (1-2), 77, 2014.

35. PANG D.B., CUI M., LIU Y.G., WANG G.Z., CAO J.H., WANG X.R., DAN X.Q., ZHOU Z.X. Responses of soil labile organic carbon fractions and stocks to different vegetation restoration strategies in degraded karst ecosystems of southwest China. Ecol. Eng., 138, 391, 2019. 